\title{
Relationship between Relative Humidity and the Dew Point Temperature in Benin City, Nigeria
}

\section{1,3, ${ }^{*}$ UKHUREBOR, KE; ${ }^{2}$ ABIODUN, IC; ${ }^{3}$ BAKARE, F}

\author{
${ }^{I}$ Department of Physics, Edo University, Iyamho, Edo State, Nigeria \\ ${ }^{2}$ Department of Physics, Federal University, Otuoke, Bayelsa State, Nigeria \\ ${ }^{3}$ Department of Physics, University of Benin, Benin City, Edo State, Nigeria \\ "Corresponding Author: ukeghonghon@gmail.com; +2348035383194
}

\begin{abstract}
The influence of weather in all aspects of human endeavours is evident in the recorded loss of lives and properties due to weather related disasters usually triggered by global climate changes. Hence, the need for the collation of information about the temporal dynamics of weather changes is of paramount interest. This research was aimed at determining the relationship between relative humidity and the dew point temperature in Benin City, Edo State, Nigeria. The dew point temperature was approximated from the measured air temperature and relative humidity with the aid of a currently self-designed weather monitoring system. The results showed that the relationship between the relative humidity and the dew point temperature were linear with significant coefficient of determination $\left(\mathrm{R}^{2}\right)$ of 0.79 . The relative humidity and the dew point temperature are prospective tools in weather prognostications and are used to express the amount of moisture in the air, this would help guide against the occurrences of climatic induced environmental disasters in our communities. (C) JASEM
\end{abstract}

https://dx.doi.org/10.4314/jasem.v21i5.22

Key words: Weather, Relative humidity, Dew point temperature, Climate.

Weather and climate changes have always been an issue of great interest; in recent times is becoming a universal concern especially its effects on our environment. It's monitoring holds great importance and has uses in several areas in our respective endeavors: which are useful in one way or the other in the course of our daily activities. Weather affects almost all aspects of human endeavors, each year many lives and properties are lost through weather related disasters and hazards caused mainly by global climate changes. There cannot be a study of the weather neither its prognostication without the knowledge of the prevailing conditions of the atmosphere. For this reason, man has always explored means of measuring different parameters of the weather. With the advancement in technology, new methods and equipment have been developed to measure, collect and monitor weather information and today a whole field of study called meteorology is dedicated to it (Karl, 2014; Akhilesh et al., 2015; Akpan et al., 2016; Ukhurebor et al., 2017). Meteorology is the science of the atmosphere. Its domain is the atmosphere of the whole universe and its practice involves the daily cooperation of every action on the universe. In meteorology, the data measured and collected are used for monitoring and forecasting the weather. Meteorologically, weather is used to describe the momentary atmospheric conditions at a certain place. It is the state of the atmosphere of a given place at a particular time. Weather describes the condition of the atmosphere over a short period of time for example, from day to day or week to week. The climate of an area is known through the average weather over a long period of time. If an area has more dry days throughout the year than wet days, it would be described as a dry climate and if a place have more cold days than hot days it would be known to have a cold climate.
Climate describes the average weather conditions over a longer period of time. In describing the atmospheric conditions of a given place at a given time, certain weather elements or parameters must be known, measured and quantified. Some of the most crucial weather elements are temperature, relative humidity, atmospheric pressure, wind speed and direction, precipitation, dew point temperature, altitude, solar or light intensity (Karl, 2014; Akhilesh et al., 2015; Akpan et al., 2016; Ukhurebor et al., 2017).

The dew point temperature is the temperature at which the moisture/liquid water (water vapor) in the air begins to condense or evaporates at same rate at which it condenses. It is the temperature at which water vapor in the air will condense into dew, frost, or water droplets given a constant air pressure. It is when the temperature at which the saturation vapour pressure and actual vapor pressure are equal (Tawhida and Hisham, 2013). Dew point is of great interest to meteorologists because it is a fundamental measure of the state of the atmosphere in terms of how much water vapor is present. Furthermore, dew point temperature can provide a fairly direct sense of how comfortable or uncomfortable warm air will feel. Dew point can also give us a reasonable starting point for estimating low temperatures the following day, as under certain conditions the low will end up pretty close to the dew point at the time of maximum temperature the day before. We can also use projections of dew point temperature to aid in prognosticating the formation of fog or dew and in the estimating rain, snow, dew, evapotranspiration, near-surface humidity and other meteorological parameters. Also, higher dew points through the lower atmosphere (especially those above $60^{\circ}$ or so) can help to support more numerous and/or intense 
thunderstorms when other factors favor their formation. The dew point is directly related to the amount of water vapour; it's directly proportional to water vapour (Raymond, 1991; Mike, 2016). Dew point temperature together with relative humidity can be used to determine the moisture content in the air. A dew point temperature below $0{ }^{\circ} \mathrm{C}$ is referred to as the frost point because frost is produced when the air cools to that temperature. It is a great weather tool in forecasting the rain, frost and fog formation as well as the probability of thunderstorms (Tawhida and Hisham, 2013). The dew point temperature is different from the relative humidity even though both are prospective tools in weather prognostications and are used to express the amount of moisture in the air. The dew point indicates how much moisture is in the air, whereas relative humidity is a percentage that indicates how saturated the air is. In other words, the higher the dew point is, the more moisture is in the air and vice versa. In addition to that: if the dew point is closer to the actual air temperature, the air becomes more and more humid; when the temperature is closer to the dew point temperature, the relative humidity approaches $100 \%$ leading to muggy conditions, and it can never be higher than the air temperature (Tawhida and Hisham, 2013).

Weather has always been a major force of nature that influenced mankind in a very authoritative approach as a result of its dynamic nature. The change in one meteorological parameter could lead to changes in almost all the other parameters. Hence, by constant and accurate measuring, monitoring, analysis, evaluating and prognosticating of these parameters would certainly create the tendencies of their acceleration and would also help guide against the occurrences of climate induced environmental disasters and the improvement of agricultural productivity in our communities (Parvez et al., 2016; Deyan et al., 2011; Okhakhu, 2014; Ukhurebor et al., 2017). The trend graphs of relative humidity and the dew point temperature against the months were drawn and scatter plots of relative humidity against the dew point temperature were fitted and are shown in Figure 1 and Figure 2 respectively. The regression equation was obtained using the curve estimation procedure to determine the relationship between relative humidity and the dew point temperature for Benin City, Edo State, Nigeria from the pooled data.

\section{MATERIALS AND METHOD}

Spontaneous measurement for air temperature and relative humidity were carried out in Benin City, Edo State Nigeria (latitude: $6^{\circ} 20^{\prime} 17^{\prime \prime} \quad \mathrm{N}$, longitude: $5^{\circ} 37^{\prime} 32^{\prime \prime}$ E) simultaneously at an approximate height of $1.5 \mathrm{~m}$ above sea level. The readings were made every hour from 8.00 am to 6.00 pm during the period of January 2016 to December 2016 using a self-designed cost effective weather monitoring system.
Thereafter, the approximation of the dew point temperature using the Thumb rule (Eqn. 1 or Eqn. 2) was carried out.

$$
\boldsymbol{T d}=\boldsymbol{T}-\left(\frac{100-R H}{5}\right)
$$

Also we can use a complex formula;

$$
T d=T n \frac{\operatorname{In}\left(\frac{R H}{100}\right)+\left(\frac{m T}{T n}+T\right)}{m-\operatorname{In}\left(\frac{R H}{100}\right)-\left(\frac{m T}{T n}+T\right)}
$$

Where $T d$ is the dew point, $T$ is the temperature, $R H$ is the relative humidity. For the temperature range $40{ }^{\circ} \mathrm{C}$ to $0{ }^{\circ} \mathrm{C}, \mathrm{Tn}=272.62{ }^{\circ} \mathrm{C}$ and $m=22.46$ while for the temperature range $0{ }^{\circ} \mathrm{C}$ to $50{ }^{\circ} \mathrm{C}, T n=243.12$ ${ }^{\circ} \mathrm{C}$ and $m=17.62$.

The dew point value can also be approximated automatically from the computer using MATLAB after receiving the temperature and relative humidity values or through online calculator (Tawhida and Hisham, 2013; Dushyant, 2013). The data of the relative humidity and the dew point temperature were analyzed using the computer packages SPSS 18.0 for Windows and Microsoft Excel version 10 while, the curve estimation procedure was used to determine the relationship between the relative humidity and the dew point temperature.

\section{RESULTS AND DISCUSSION}

Table 1 and Table 2 are the measured air temperature and relative humidity respectively and Table 3 contained the approximated dew point temperature accordingly. These values were in good conformity with weather data obtained from other sources (the Nigerian Meteorological Agency; NMA and online weather reports). The mean total relative humidity for the year 2016 was found to be $73.30 \%$ while the mean total dew point temperature was $19.70^{\circ} \mathrm{C}$. The results of this study also showed that the dew point temperature for Benin City, Edo State, Nigeria was as low as $13^{\circ} \mathrm{C}$ during the month of January, 2016 which was also the month of the lowest relative humidity $(40 \%)$. The highest level of the dew point temperature $\left(26^{\circ} \mathrm{C}\right)$ and relative humidity $(95 \%)$ were during July, 2016 which is the month of peak rains.

The relationship between the relative humidity and the dew point temperature were linear with significant coefficient of determination $\left(\mathrm{R}^{2}\right)$ of 0.79 and the result was in conformity with some other findings like the work of Tawhida and Hisham (2013); Lawrence (2005). This implies that an increase or decrease in the relative humidity would also bring about an increase or decrease in the dew point and verse versa. We therefore arrived at the finding that the relative humidity and the dew point 
temperature have a direct relationship in Benin City, Nigeria.

Table 1: Air Temperature for 2016

\begin{tabular}{ll}
\hline \multicolumn{1}{c}{ Month } & Measured Average Temperature $\left({ }^{\circ} \mathrm{C}\right)$ \\
& \\
January & 25.00 \\
February & 30.00 \\
March & 30.00 \\
April & 28.00 \\
May & 27.00 \\
June & 26.00 \\
July & 26.00 \\
August & 26.00 \\
September & 26.00 \\
October & 27.00 \\
November & 27.00 \\
December & 23.00 \\
Mean Total & $\mathbf{2 6 . 8 0}$ \\
\hline
\end{tabular}

Table 2 Relative Humidity for 2016

\begin{tabular}{ll}
\hline Month & Measured Average Humidity $(\%)$ \\
& \\
January & 40.00 \\
February & 48.00 \\
March & 78.00 \\
April & 85.00 \\
May & 92.00 \\
June & 92.00 \\
July & 95.00 \\
August & 78.00 \\
September & 78.00 \\
October & 68.00 \\
November & 68.00 \\
December & 58.00 \\
Mean Total & $\mathbf{7 3 . 3 0}$ \\
\hline
\end{tabular}

Table 3: Dew Point Temperature for 2016

\begin{tabular}{ll}
\hline Month & Approximated Average Dew Point $\left({ }^{\circ} \mathrm{C}\right)$ \\
January & 13.00 \\
February & 19.60 \\
March & 25.60 \\
April & 25.00 \\
May & 25.40 \\
June & 24.40 \\
July & 26.00 \\
August & 21.60 \\
September & 21.60 \\
October & 20.60 \\
November & 20.60 \\
December & 14.60 \\
Mean Total & 19.70 \\
\hline
\end{tabular}

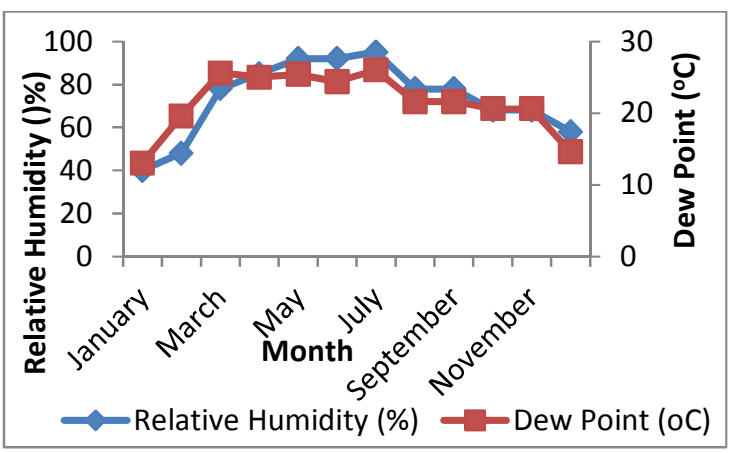

Fig 1: The trend graph for Relative Humidity (\%) and Dew Point Temperature $\left({ }^{\circ} \mathrm{C}\right)$ at Benin City, Nigeria for 2016

Conclusion: The change in one meteorological parameter could lead to change in almost all the other climatic parameters. From this research it has been shown that the relative humidity and the dew point temperature had a linear relationship which can be

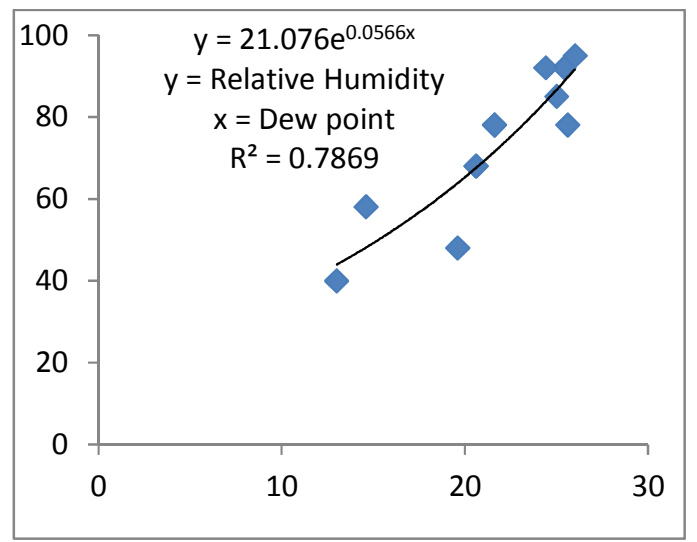

Fig 2: The relationship between Relative Humidity (\%) and Dew Point Temperature $\left({ }^{\circ} \mathrm{C}\right)$ at Benin City, Nigeria for 2016.

obtained with an acceptable level of accuracy using empirical regression models. We therefore recommend that further research work should be carried out so as to determine the relationships among the different climatic environmental parameters. 
Acknowledgement: The authors are grateful to Mrs. UK-Eghonghon Gladys for her assistance during the measurement process.

\section{REFERENCES}

Akhilesh, C; Tejas, B; Chinmay, K; Mahalaxmi, B (2015). Bluetooth Based Weather Station. International Journal of Engineering Trends and Technology, Volume 28 Number 2.

Akpan, V.A; Osakwe, R.O. A; Ekong, S.A (2016). A Hypothetical Database-Driven Web-Based Meteorological Weather Station with Dynamic Datalogger System. Journal of Information Engineering and Applications ISSN 2224-5782 (print) ISSN 2225-0506 (online) Vol.6, No.1.

Deyan, L; Tsvetomiv, G; Kamen, K; Aneliya, M; Valentin, D (2011). Embedded Automatic Weather Station. Elektronika, Miesiecznik naukowo-techniczny Stowarzyszenia Elektrykow Polskich ISSN 0033-2089.

Dushyant, P; Sanjeev, G (2013). Measurement And Transmission Of Atmospheric Parameters Using Radio Frequency. Communication International Journal Of Technical Research And Applications E-ISSN: 2320-8163, Volume 1, Issue 3, page 8590.

Karl, I.E (2014). Portable Weather Station. Final thesis for B.Sc. degree School of Engineering and Natural Sciences, Keilir Institute of Technology University of Iceland Reykjanesbar.

Lawrence, M.G (2005). The Relationship between Relative Humidity and the Dew point Temperature in Moist Air: A Simple Conversion

age 1-6 and Applications. Bulletin of America Meteorology Society, 86, page 225-233.

Mike, M (2016). Capitol Broadcasting Company, Raleigh, North Carolina, USA.

Okhakhu, P.A(2014). Meteorological Services for Disaster Risk Prevention and Mitigation in Nigeria. Journal of Environment and Earth Science ISSN 2224-3216 (Paper) ISSN 22250948 (Online) Vol.4, No.8.

Parvez S. H; Saha J. K; Hossain M. J; Hussain H; Ghuri Md. M. A; Chowdhury T. A; Rahman Md. M; Shuchi N. Z; Islam A; Hasan M; Paul, B (2016). A Novel Design and Implementation of Electronic Weather Station and Weather Data Transmission System Using GSM Network. Article in WSEAS Transactions on Circuits and Systems

Raymond, A.S (1991). College Physics, Saunders College Publishing, Harrisonburg, Virginia, USA.

Tawhida, A.Y; Hisham M.M.T (2013). The Relationship between Relative Humidity and the Dew point Temperature in Khartoum State, Sudan. Journal of Applied and Industrial Sciences, 2013, 1 (5): 20-23, ISSN: 2328-4595 (PRINT), ISSN: 2328-4609.

Ukhurebor, K.E; Azi, S.O, Abiodun, I.C; Enoyoze, E (2017). Approximation of the Dew Point Temperature Using a Cost Effective Weather Monitoring System. Physical Science International Journal 14(3), Article no.PSIJ.32862 ISSN: 2348-0130 DOI: 10.9734/PSIJ/2017/32862; P 